\title{
Conflitos em escolas públicas em Portugal: análise de um programa de governo
}

Ângela Maria Martins ${ }^{a}$
Mariana Gaio Alves ${ }^{b}$

\section{Resumo}

Este artigo examina elementos no processo de constituição de significados atribuídos por atores escolares de escolas públicas localizadas em contextos vulneráveis, em Portugal, às situações de indisciplina, conflito e violência, em torno do seguinte questionamento: quais são as ações encetadas para enfrentá-las e suas percepções acerca desses fenômenos? As escolas selecionadas para o estudo integram o programa TEIP (Territórios de Intervenção Prioritária), desde 1996. Trata-se de estudo qualitativo e exploratório, com base em levantamento e análise de informações de documentos oficiais e da legislação, além de entrevistas realizadas com equipes compostas por profissionais responsáveis pela sua implementação. Considera-se a relevância de compreender percepções de atores educacionais envolvidos em fatos e situações de conflitos em escolas públicas.

Palavras-chave: Políticas públicas de educação. Programas de governo. Indisciplina. Conflito e violência em escolas públicas.

\section{Introdução}

Este artigo examina resultados de pesquisa ${ }^{1}$ realizada em Portugal, como desdobramento de investigação maior que apresentava como propósito analisar o Programa Sistema de Proteção Escolar (SPE), implementado na rede pública de escolas do Estado de São Paulo, por meio da Resolução SE 19, de 12/02/2010 (SÃO PAULO, 2010), cujo objetivo é instaurar, na rede pública de escolas

\footnotetext{
a Universidade Cidade de São Paulo, São Paulo, SP, Brasil.

b Instituto de Educação da Universidade de Lisboa, Lisboa, Portugal.

1 Pesquisa financiada com Bolsa de Estágio de Pesquisa no Exterior da Fundação de Amparo à Pesquisa do Estado de São Paulo (FAPESP).
} 
estaduais paulistas, ações para mediar e resolver conflitos em escolas que optam por se inscrever no referido programa, e que estão localizadas em regiões de vulnerabilidade socioeconômica.

Nessa direção, este artigo - inserido no estudo mais amplo citado - examina elementos no processo de constituição de significados atribuídos por atores escolares de escolas públicas, localizadas em contextos vulneráveis, em Portugal às situações de indisciplina, conflito e violência, em torno do seguinte questionamento: quais são as ações encetadas para enfrentá-las e suas percepções acerca desses fenômenos?

As escolas selecionadas integram o programa TEIP (Territórios de Intervenção Prioritária), desde 1996, cujo objetivo central é desenvolver estratégias específicas em escolas localizadas em áreas segregadas, com vistas a minimizar efeitos do contexto socioeconômico desfavorecido, no que se refere aos resultados escolares dos alunos.

\subsection{Violência, indisciplina e conflito: nuances de estudos}

A violência na escola é frequentemente retratada como um fenômeno que surge associado a certa degradação civilizacional e à massificação escolar (em especial tendo em conta a universalização da escolaridade obrigatória), bem como a noções que veem as escolas como locais que poderiam proteger de possíveis riscos a infância e a juventude - segmentos que merecem atenção especial de proteção (Sebastião, 2013).

Debarbieux e Blaya (2002) indicam dificuldades em delimitar cientificamente o objeto "violência" que, para eles, abrangeria desde agressões graves até as pequenas incivilidades que acontecem na escola. Ao mesmo tempo em que esta definição pode tornar-se impensável, devido aos inúmeros tipos de situações envolvidas, também pode acabar excluindo a experiência de algumas vítimas no processo de reflexão sobre o problema. A forte influência da mídia sobre os pesquisadores, apontada pelo autor, também deve ser considerada, pois pode acabar conduzindo as pesquisas acadêmicas a uma pré-fabricação social da violência nas escolas, em alguns casos, endossando o que lhes é apresentado, muitas vezes de forma exacerbada, pelos meios de comunicação.

Vasconcelos (2017), com base em estudos realizados na área e sistematizados por ele, discute diversos efeitos de violências sofridas por alunos - sobretudo por aqueles com mães vítimas da violência de gênero - que repercutem em baixos rendimentos na escola e no absenteísmo escolar. Nas palavras do autor (p. 902) 
"[...] não pode dar certo tratar essas consequências com mais violência, como as famosas humilhações públicas ou até castigos corporais que, no fundo, transmitem a mensagem de que o aluno é o culpado pelo seu sofrimento". Prossegue, lançando mão de estudo realizado por Martins, Machado e Bravo (2016), afirmando que mais conflito e intolerância também não resolvem, e que, frequentemente, atores escolares tendem a transferir responsabilidade nessas situações.

De qualquer forma, a violência pode ser compreendida como todas as violações dos direitos civis (vida, propriedade, liberdade de ir e vir, de consciência e de culto); políticos (direito a votar e a ser votado, ter participação política); sociais (habitação, saúde, educação, segurança); econômicos (emprego e salário); e culturais (direito de manter e manifestar sua própria cultura) (Comunidade Internacional de Direitos Humanos). Ceccon et al. (2009), com base em extenso balanço de literatura sobre o tema, argumentam que escolas seguras são aquelas nas quais o equilíbrio prevalece, embora haja níveis de instabilidade. Esse equilíbrio promove um sentimento de segurança, essencial à aprendizagem, pois necessidades psicológicas básicas dos alunos e dos membros da equipe escolar estão sendo atendidas.

Sebastião, Alves e Campos $(2003 ; 2010)$ afirmam que, em Portugal, ocorrem insistentes debates sobre as questões que afetam o sistema de educação nacional, imensamente ampliados pela midia, sobretudo no que se refere ao termo bullying. Os autores identificam que o referido termo pode descrever qualquer tipo de situação de violência, ou mesmo de indisciplina, alterando, inclusive, o significado que o qualifica como um fenômeno que envolve agressões feitas de forma sistemática e intencional.

Na contemporaneidade, é também relevante considerar que as tecnologias, designadamente celulares e internet, permitem a manifestação e ampliação de situações de conflito - por meio do cyberbullying (SLONJE; SMITH, 2008) - que podem prolongar-se na interação face a face. Em estudo realizado em Portugal, Ventura, Vico e Ventura (2016) enfatizam que nem todo conflito, indisciplina ou violência pode ser classificada como bullying. Os autores analisam que crianças precisam aperfeiçoar competências sociais para aprender a conviver mais harmoniosamente com os seus pares e resolver conflitos sem usar de violência. Contudo, ainda que gestores escolares monitorem essas situações, nem sempre é possível apreender todos os elementos "de um grupo (que) parecem estar a divertir-se", pois talvez estejam fazendo "chacota de um dos colegas por este ser de classe social diferente (mais baixa ou mais elevada do que a do restante do grupo), por usar óculos, por usar aparelho de correção 
ortodôntica, ou mesmo simplesmente por responder corretamente quando os professores lhe colocam perguntas (p. 998).

Desse modo, partimos nessa pesquisa do pressuposto de que situações de indisciplina e conflito são elementos integrantes do cotidiano de qualquer escola, importando compreender como é que unidades localizadas em regiões vulneráveis se organizam para prevenir e regular tais ocorrências. Assim sendo, privilegiouse ouvir profissionais responsáveis pelos programas em escolas inseridas no programa em pauta, explorando as respectivas perspectivas e lógicas de ação e, adicionalmente, contribuindo para compreender significados da sua atuação em escolas na contemporaneidade. Aliás, numa meta-análise de pesquisas doutorais, realizadas em Portugal, reúnem-se indícios de que a investigação sobre conflitos e convivência na escola tem privilegiado ouvir os alunos, indicando a relevância do desenvolvimento de pesquisas que considerem o que pensam os outros atores escolares, no que se refere ao cumprimento de diretrizes de programas de governo (Alves, 2016).

A centralidade atribuída aos modos de organização e funcionamento das escolas, na abordagem delineada, reforça a importância de refletir sobre o papel de professores e diretores, nomeadamente, enquanto atores que se veem envolvidos diretamente em situações de indisciplina e violência nas dinâmicas escolares. Enquanto algumas perspectivas conservadoras argumentam que estamos perante uma alegada perda de autoridade de professores e diretores, na sociedade contemporânea, outras visões defendem que a autoridade do professor, mais do que como exercício de controle e imposição sobre os outros, deve ser entendida como uma dinâmica relacional, na qual a necessidade de articular conteúdos, relações e finalidades na ação do professor, ou em outros termos, a articulação entre meios e fins da educação, é fulcral para estabelecer o que é desejável para uma educação de qualidade (Biesta, 2012).

\section{Metodologia}

A investigação configura-se como um estudo qualitativo e exploratório, ancorado na perspectiva microssociológica. Toma como referência o interacionismo simbólico, que leva em consideração o modo como pensam os atores sociais, iluminando as significações que estes colocam em prática para edificar suas relações sociais, portanto, o conhecimento sociológico se fundamenta, nessa perspectiva, na prática dos indivíduos. Na mesma direção, destaca-se a noção de definição da situação, quando "os significados sociais não são inerentes às instituições ou aos objetos sociais tomados em si mesmos, independentemente dos atores, mas, ao contrário, 
são atribuídos aos acontecimentos sociais, pelos indivíduos, no decorrer de suas interações" (LAPASSADE, 2005, p. 20).

Tendo em vista que o foco do estudo se refere às situações de indisciplina característica no comportamento de jovens estudantes - que podem redundar em conflitos e, em última instância, em violência, tomou-se ainda como referência no âmbito das teorias tributárias da Escola de Chicago $^{2}$ - as denominadas teorias da "etiquetagem" ou da "designação", processos pelos quais os desviantes são rotulados pela sociedade, sem levar em consideração todos os elementos que compõem a essência do próprio ato desviante. Nessa direção, é difícil encontrar consenso para definir claramente o que seria a infração de uma regra, ou mesmo o que seria uma regra no interior das sociedades complexas modernas. Ser nomeado como desviante advém de uma variedade de aspectos sociais configurados sob determinação legal e normativa de órgãos institucionais. Assim, jovens podem ser designados como portadores de condutas desviantes, sem necessariamente terem essas características, sendo rotulados em situações que tornam mais difícil levarem, posteriormente, rotinas normais (BECKER, 2008).

Realizou-se, ainda, análise de diretrizes dos documentos oficiais e da legislação que ancoram o programa TEIP; a discussão de resultados de estudos que focalizam o tema e as entrevistas realizadas em agrupamentos de escolas em Portugal.

Partiu-se do pressuposto que a entrevista qualitativa pode ser um "instrumento para mapear e compreender este mundo vivencial do entrevistado", fornecendo "dados básicos para a compreensão detalhada das crenças, atitudes, valores e motivações, em relação aos comportamentos das pessoas em contextos sociais específicos" (BAUER; GASKEL, 2014, p. 64).

Foram entrevistados dez profissionais que integram equipes de gestão de três agrupamentos de escolas, localizadas na área de Lisboa, por meio de roteiro semiestruturado: num agrupamento da zona norte de Lisboa foram entrevistadas duas adjuntas do diretor, bem como uma coordenadora do plano TEIP e uma coordenadora de diretores de turma; num agrupamento situado na zona sul de Lisboa foram entrevistadas a diretora e duas técnicas (uma assistente social

\footnotetext{
2 A Universidade de Chicago, fundada em 1892, desenvolveu um conjunto de estudos designados pela Escola de Chicago, cujo traço marcante era a multidisciplinaridade, envolvendo pesquisas em sociologia, antropologia, psicologia, ciência política, filosofia, economia e arquitetura (GOLDEMBERG, 2004). O Departamento de Sociologia e Antropologia realizou produções relevantes em ciências humanas e sociais, algumas delas baseadas em pesquisas etnográficas. As técnicas são utilizadas até hoje: análise de documentos pessoais (cartas e diários); análise de documentos públicos (artigos de jornais; arquivos; fichários); trabalho de campo baseado em questionários estruturados e semiestruturados; entrevistas (incluindo autobiografias); estudo de caso; observação participante; painéis de discussão.
} 
e uma mediadora); num outro agrupamento também situado na zona sul de Lisboa foi entrevistada a diretora, a sub-diretora e um educador social. As falas dos entrevistados embasam a análise encetada por meio da triangulação com documentos oficiais, medidas legais e a literatura da área, porém, não serão expostas no texto.

É preciso ressaltar a relevância de apreender as interações entre os atores escolares e o modo como essa dinâmica cotidiana pode afetar a implementação de programas e projetos de governo, assim como observar de que forma as unidades constroem aprendizagens próprias em sua efetivação.

A análise de conteúdo das informações coletadas baseou-se nos pressupostos de Bardin (1994), que preconizou um conjunto de estratégias e técnicas utilizadas para análise das comunicações sistematizadas, organizadas por algum critério de semelhança. Com base na triangulação de fontes de informação e a partir das inferências realizadas por meio da análise de conteúdo, foram identificadas duas dimensões de análise: o programa de governo (diretrizes e normativas), indisciplina, conflito e violência (significados atribuídos por atores escolares de escolas integrantes do TEIP).

\subsection{O Programa de governo: diretrizes e normativas}

O programa TEIP (Territórios de Intervenção Prioritária) surgiu em 1996 e é uma iniciativa do governo nacional, tendo, por inspiração, medidas políticas semelhantes que haviam começado a ser implementadas previamente em França (Zones d'Éducation Prioritaire) e no Reino Unido (Education Action Zones). A característica comum desse conjunto de medidas de política educativa consiste na procura de rentabilizar instalações, serviços e recursos para o desenvolvimento de estratégias específicas em escolas localizadas em áreas segregadas, com vistas a minimizar efeitos do contexto socioeconómico desfavorecido no que se refere aos resultados escolares dos alunos em escolas localizadas nessas áreas. Nesse sentido, em Portugal, as escolas TEIP têm acesso a instrumentos nem sempre disponíveis nas demais escolas públicas, como sejam equipamentos e professores em maior número e ainda o apoio de outros profissionais (psicólogos, assistentes sociais e mediadores).

Uma avaliação qualitativa do programa, realizada pelo próprio Ministério da Educação, em 2010, evidenciou que, em Portugal, o programa tem efeitos positivos na redução das situações de violência e das taxas de abandono escolar, embora não tivessem reunido indícios de significativas melhorias dos resultados acadêmicos, permanecendo as classificações dos alunos, em exames nacionais, 
claramente abaixo da média registada no país. No que se refere especificamente às situações de conflito nas escolas, a avaliação destaca um aumento do número de registos de situações de indisciplina, porém, com uma redução do nível de gravidade dessas ocorrências, o que indica possível ampliação, quer da capacidade de identificação e registo de situações de indisciplina quer de resposta a estas situações ${ }^{3}$.

Essa avaliação, realizada em 2010, incidiu sobre as duas primeiras fases do programa TEIP, sendo que, nos anos letivos 2012/13, teve início o terceiro programa. De acordo com o Despacho Normativo no 20 (PORTUGAL, 2012), publicado em Diário da República em 3 de outubro de 2012, “justifica-se a criação de um terceiro programa TEIP mais concentrado em torno especialmente das ações que as escolas identificaram como promotoras da aprendizagem e do sucesso educativo, de modo a assegurarem maior eficiência na gestão dos recursos disponíveis e maior eficácia nos resultados alcançados". No quadro do programa TEIP cada escola deverá elaborar o seu próprio Plano de Melhoria, no qual se identificam, na escola e na comunidade, medidas e ações de intervenção que assegurem a concretização dos objetivos do programa TEIP: promover "a qualidade da aprendizagem e dos resultados escolares dos alunos"; "reduzir o abandono, absenteísmo e indisciplina dos alunos"; favorecer a "transição da escola para a vida ativa"; afirmar a "intervenção da escola como agente educativo e cultural central na vida das comunidades em que se insere" (Artigo $3^{\circ}$ do Despacho Normativo $n^{\circ}$ 20/2012).

O Plano de Melhoria deve ser articulado com o Projeto de Intervenção do Diretor de cada escola (o qual é apresentado quando o mesmo se candidata a esse cargo de direção para o qual é eleito pela comunidade escolar), bem como com o Projeto Educativo da Escola que é aprovado pelo respectivo Conselho Geral composto por representantes de professores, funcionários, alunos, encarregados de educação e das autoridades locais. Na elaboração dos planos de melhoria, necessários à concessão de apoios, através do programa TEIP, devem ser ponderados as circunstâncias e os interesses específicos da comunidade envolvente da escola, bem como contempladas as intervenções de diversos parceiros, como as associações de pais, os municípios locais, os centros de saúde e ação social, empresas, associações culturais e desportivas, entre outros.

O programa TEIP abrange apenas uma pequena parte dos agrupamentos de escolas/escolas não agrupadas que, em Portugal, constituem a rede pública de

\footnotetext{
3 Informação retirada de: http://www.dge.mec.pt/sites/default/files/EPIPSE/teip_em_numeros_outubro_2010. pdf consultada em 22 de fevereiro de 2017.
} 
ensino básico e secundário. De facto, as escolas TEIP abrangem cerca de 10\% dos alunos do ensino básico e secundário em Portugal e distribuem-se por todas as regiões do continente: 49, no Norte, 13, no Centro, 46, em Lisboa e Vale do Tejo, 18, no Alentejo e 11, no Algarve. Ressalte-se que, em Portugal, as escolas podem constituir-se como unidades organizacionais isoladas (escolas não agrupadas), mas, a grande maioria encontra-se incluída num conjunto de várias escolas que estão geograficamente próximas umas das outras e que partilham recursos financeiros e administrativos (agrupamentos de escolas).

Existem escolas que já integravam o programa TEIP anteriormente sendo que, no quadro da terceira fase que se iniciou em 2012/13, o Ministério da Educação (através da Direção Geral de Educação) convidou outras escolas a participarem, tendo por base a análise dos respectivos indicadores de desempenho e das características sociais do meio envolvente da escola (Artigo $6^{\circ}$ do Despacho Normativo $n^{\circ} 20$ (PORTUGAL, 2012). Consequentemente, foi alargado o número de escolas abrangidas pelo programa TEIP que se cifra, atualmente ${ }^{4}$, em 137 agrupamentos de escolas/escolas não agrupadas localizadas em territórios económica e socialmente desfavorecidos, marcados pela pobreza e exclusão social, nos quais a violência, a indisciplina, o abandono e o insucesso escolar mais se manifestam.

A coordenação das várias intervenções em cada uma das escolas TEIP é assegurada por um equipa multidisciplinar (ver Artigo $10^{\circ}$ do Despacho Normativo $n^{\circ} 20 / 2012$ ) composta pelo diretor do agrupamento de escolas e por outros docentes enquanto coordenadores de departamento, um responsável pela coordenação do plano, um elemento da equipa de autoavaliação do agrupamento e outros elementos da direção, cuja inclusão na equipa se julgue adequada, podendo ainda participar nas reuniões os peritos externos (geralmente professores ou investigadores de instituições de ensino superior). O diretor do agrupamento é eleito pela comunidade escolar e é sempre um professor, sendo que os professores das escolas públicas são contratados, na sua maioria, por concurso nacional e apenas uma parte diminuta por contratação de escola, estando enquadrados em carreiras formalmente estabelecidas pela legislação nacional. A inclusão no programa TEIP permite que estas escolas contratem diretamente outros profissionais que entendam ter o perfil mais adequado para desenvolver as ações e medidas de intervenção previstas no Plano de Melhoria, como sejam psicólogos, assistentes sociais, mediadores ou educadores sociais, ainda que não existam carreiras formalmente estabelecidas para esses técnicos nas escolas.

\footnotetext{
4 Informação obtida na página do Ministério da Educação: http://www.dge.mec.pt/teip consultada em 22 de outobro de 2018.
} 


\subsection{Indisciplina, conflito e violência: significados atribuídos por atores escolares de escolas integrantes do TEIP.}

Nas escolas portuguesas, as situações de violência ainda não assumem uma expressão alarmante, ou não se evidencia que tenham vindo a agravar-se nos últimos tempos. Não configuram um fenômeno que redunde em casos de delito grave, tais como os que envolvem alunos (as) em tráfico de drogas. Não obstante, a gestão das situações de conflito e convivência nas escolas é uma preocupação cotidiana, e, no caso das escolas TEIP visitadas, estas subjacente as ações de intervenção na própria escola e na relação com a comunidade envolvente.

Destaca-se a existência de Gabinetes de Apoio ao Aluno e à Família que complementam a ação dos professores, mediando conflitos entre alunos ou entre alunos e professores que emergem nas salas de aulas e/ou nos recreios e também fora da escola. Assinalem-se também as visitas aos domicílios dos alunos com vistas a aproximar a escola dos pais e familiares, bem como para permitir um melhor conhecimento e acompanhamento do contexto e percurso dos alunos. Tal como reconhecem alguns entrevistados, essas ações configuram um alargamento do papel da escola e do professor, no sentido em que a tarefa de ensinar crianças e jovens não dispensa a intervenção sobre os seus contextos de vida dentro e fora da escola, com o objetivo de promover as aprendizagens e prevenir os conflitos.

Para a realização desse tipo de ações, dentro e fora da sala de aula e da escola, é fundamental o contributo dos técnicos (psicólogo, assistente social, sociólogo) que cada TEIP contrata, em função das atividades previstas no respectivo Plano de Melhoria, e que integram a equipe multidisciplinar em conjunto com os professores. Porém, nas falas dos entrevistados sobressaem as dificuldades que decorrem de muitas vezes existir uma elevada rotatividade desses profissionais em cada escola, pelo fato de terem contratos de trabalho pontuais e não estarem integrados em carreiras profissionais. Há um tempo absolutamente necessário de convivência para que o técnico conheça bem a comunidade escolar e esteja apto a desenvolver o seu trabalho da forma mais adequada e eficaz. Apesar disso, sublinhe-se que a existência de autonomia para delinear um Plano de Melhoria e para decidir a constituição da equipe multidisciplinar, emerge como uma particularidade.

Outra questão recorrentemente, apontada nas entrevistas realizadas nas escolas de Lisboa, se refere às crescentes práticas de cyberbullying, corroborando achados de estudos na área, pois as tecnologias de informação - por meio das redes sociais - possibilitam ao aluno a divulgação de ofensas a colegas, professores e famílias. 
Igualmente chama a atenção o fato de que os profissionais entrevistados denotam certo desencanto e desistência no exercício do cargo - elementos que podem indicar um esgotamento no significado da docência - envolvendo funções de gestão como profissão valorizada pela sociedade e considerada prioritária nas agendas de governo, dados que ratificam pesquisas na área, indicando uma crise de identidade profissional no escopo de mudanças sociais, culturais e econômicas e que apontam a necessidade da construção de um novo significado para essa carreira.

Há alguns fatores que incidem na satisfação/insatisfação na carreira do magistério, conforme se constatou em pesquisa realizada anteriormente: a falta de apoio à atividade profissional docente desde os primeiros anos da carreira, os baixos níveis salariais, a precarização do emprego e o excesso de trabalho administrativo são geralmente referidas como dificuldades sentidas pelos professores relativamente às suas condições de trabalho. Num contexto de envelhecimento do grupo profissional dos professores em Portugal, estas dificuldades reforçam a decisão de muitos de se retirarem da profissão, optando pela aposentadoria (ALVES; AZEVEDO; GONÇALVES, 2014)

O desencanto com a profissão, por parte dos profissionais entrevistados, relaciona-se com condições de trabalho e salário, nomeadamente com a ausência de progressões na carreira e com os cortes financeiros, que nos últimos anos, afetaram todos os setores da administração pública reduzindo os rendimentos auferidos pelos trabalhadores e diminuindo os orçamentos para a realização dos mais diversos projetos extracurriculares.

Vale destacar um aspecto relevante que emergiu das falas dos entrevistados correspondente à presença significativa de alunos imigrantes e ao fato de como esta situação potencializa fortes contrastes culturais que originam conflitos entre alunos, entre alunos e professores ou mesmo entre a escola e as famílias. Conforme evidencia Hortas (2013), o número de alunos imigrantes que frequentam as escolas portuguesas cresceu significativamente nos últimos anos e a diversificação das origens com a chegada de população do continente asiático (China, Índia, Paquistão, Bangladesh), do Brasil e da Europa de Leste logrou relevância, confrontando a escola com novos públicos. No entanto, persiste um grande desconhecimento sobre as implicações da presença de imigrantes nas escolas portuguesas e as estratégias de integração que as escolas têm implementado, ainda que, ao nível político, a legislação referente à integração de alunos de origem estrangeira no sistema de ensino português tenha sido reformulada desde finais dos anos de 1990, contemplada no conjunto de medidas de intervenção expressos nos Planos para a Integração dos Imigrantes, por meio dos quais o Estado define um plano 
de compromissos em diferentes domínios sociais. Em suas palavras, "a escassa divulgação de informação estatística sobre (...) alunos estrangeiros (...), o seu desempenho escolar e os percursos que realizam tem conduzido, por vezes, a generalizações e construções estereotipadas em relação ao seu perfil, associadas a situações de insucesso e violência escolar, divulgadas frequentemente pelos órgãos de comunicação social”' (p. 73).

É preciso ficar atento ao clima de medo e insegurança que pode promover (re) ações negativas na escola, constituindo estigmas, em relação às diferentes origens étnicas dos alunos, considerados como potenciais delinquentes juvenis.

\section{Considerações finais}

Os entrevistados apontaram a necessidade de conhecer a comunidade onde a escola se insere, aprofundar conhecimentos e agregar informações sobre processos de mediação de problemas e conflitos em contextos escolares vulneráveis. No caso de implementação de programas de governo, cujos objetivos se voltam ao atendimento de segmentos mais fragilizados da população, saber ouvir as "partes", se posicionar e encaminhar soluções coerentes às demandas locais é essencial, pois essas unidades tornam-se, muitas vezes, foco de atenção da mídia, ampliando a responsabilidade das equipes de gestores, professores e funcionários.

Afirmaram ter dificuldades para lidar com valores sociais complexos no cenário contemporâneo e construir princípios e relações de respeito, pois não se sentem suficientemente fundamentados para enfrentar situações desafiadoras, sobretudo no que se refere às condições de vulnerabilidade social e econômica, aos quais estão expostos os alunos e suas famílias, bem como aos valores que configuram e permeiam suas práticas cotidianas. Enfatizaram a ausência de interesse identificada em parte dos alunos para seguir na escolaridade regular e lograr alguma mobilidade social por meio da educação.

Os entrevistados apontaram, ainda, aspectos que podem interferir no interesse em se manter nos bancos escolares: ausência de perspectiva de futuro frente às condições econômicas e culturais vivenciadas pelos alunos; novas configurações familiares que se refletem na escola; o fato de se "perceberem" marginalizados na sociedade, o que pode potencializar sentimentos de fracasso e problemas de autoestima, aprofundando a ausência de sentido do papel social da escola no cenário contemporâneo; dificuldades para lidar com culturas juvenis que envolvem diferentes linguagens musicais, tipos de roupas, códigos de comunicação; ausência de formação adequada para mediar situações preconceituosas no que se refere 
a opções sexuais, gênero, etnias e religião, assim como a situações específicas configuradas pelos processos migratórios no continente europeu.

As falas corroboram estudo realizado por Frota (2007, p.156), ao analisar a questão da juventude inserida na sociedade contemporânea, afirmando que "sob a ênfase do mercado e do consumo, envolvida nas questões tecnológicas e nas mudanças do padrão social e culturas das massas, a juventude vem sendo colocada em situação de grande vulnerabilidade social". Além do mais, na perspectiva da noção de subcultura popular, urbana e adolescente - construída pela Escola de Chicago entre os anos de 1920 a 1940, sobre comportamentos, valores, linguagem, roupas e práticas - os jovens, na falta do que fazer e/ou na ausência de sentido das tarefas escolares, recorrem a incivilidades e a atos desviantes, ancorados por seus pares, o que não concretiza, contudo, práticas delituosas ${ }^{5}$.

Outro ponto comum que merece destaque diz respeito à aprendizagem institucional das escolas quando localizadas em contextos vulneráveis, pois todos os entrevistados afirmaram a necessidade de encetarem a construção de um ambiente acolhedor para incluir alunos, famílias e comunidades que não detêm os mesmos códigos e valores sociais e culturais que orientam as práticas escolares, configurando desafios difíceis de serem enfrentados no trabalho cotidiano, sobretudo quando se trata de trabalhar com alunos provenientes de outros países.

Em cenário de incertezas, surge como primeira reação nos profissionais da educação o sentimento de perplexidade diante de conflitos e violência, seguido de tensão muitas vezes permeada por agressividade reativa, potencializando inseguranças e angústias. Assim, a insatisfação de estar na profissão pode tomar dimensão preocupante, prejudicando trocas com os alunos e com os pares na escola. Professores e diretores são referenciais para os alunos e se estão desmotivados, dificilmente passarão uma imagem positiva do trabalho escolar e encetarão esforços para reorganizar práticas escolares que renovem ou ressignifiquem o papel da escola.

\footnotetext{
5 Essas questões foram amplamente discutidas em: Martins, Bravo e Oliveira (2018).
} 


\title{
Conflicts at public schools in Portugal: analysis of a government program
}

\begin{abstract}
This article examines elements in the process of constitution of meanings attributed to situations of indiscipline, conflict and violence by public school students located in vulnerable contexts in Portugal. The main question guiding the research is: what are the actions taken to face this type of situations and what are the perceptions about these phenomena? The schools selected for the study are part of the TEIP (Priority Intervention Territories) program since 1996. This is a qualitative and exploratory study, based on a survey and analysis of information from official documents and legislation, as well as on interviews at schools with a team composed of professionals responsible for its implementation. The relevance of understanding perceptions of educational actors involved in facts and situations of conflicts in public schools is considered.
\end{abstract}

Keywords: Public educational policies. Government programs. Indiscipline. Conflict and violence at public schools.

\section{Conflictos en escuelas públicas de Portugal: análisis de un programa de gobierno}

\section{Resumen}

Este artículo examina elementos en el proceso de formación de significados asignados por actores del sistema escolar de las escuelas públicas ubicadas en contextos vulnerables en Portugal, frente a situaciones de indisciplina, conflicto y violencia, en torno a la siguiente pregunta: ¿cuáles son las medidas adoptadas para enfrentarlas y cuáles son las percepciones acerca de esos fenómenos? Las escuelas seleccionadas para el estudio integran el programa TEIP (Territorios de Intervención Prioritaria) desde 1996. Se trata de un estudio cualitativo y exploratorio, con base en el levantamiento y análisis de informaciones de documentos oficiales y de la legislación, además de entrevistas realizadas con equipos compuestas por profesionales responsables de su implementación. Se considera la relevancia de comprender percepciones de actores educativos involucrados en hechos y situaciones de conflictos en escuelas públicas.

Palabras clave: Políticas públicas de educación. Programas de gobierno. Indisciplina. Conflicto y violencia en escuelas públicas. 


\section{Referências}

ALVES, M. G. Viver na escola: indisciplina, violência e bullying como desafio educacional. Cadernos de Pesquisa, v. 46, n. 161, p. 594-613, jul./set. 2016. https://doi.org/10.1590/198053143679

ALVES, M. G.; AZEVEDO, N.; GONÇALVES, T. Satisfação e situação profissional: um estudo com professores nos primeiros anos de carreira. Educação e Pesquisa, v. 40, n. 2, p. 365-82, abr./jun. 2014. https://doi.org/10.1590/S1517-97022014005000002

BARDIN, L. Análise de conteúdo. Lisboa: Setenta, 1994.

BAUER, M. W.; GASKELL, G. (orgs.). Pesquisa qualitativa com texto, imagem e som: um manual prático. 12. ed. Petrópolis: Vozes, 2014.

BECKER, H. S. O estudo do desvio: problemas e simpatias. In: Outsiders: estudos de sociologia do desvio. Rio de Janeiro: Zahar, 2008. p. 169-78.

BIESTA, G. J. J. Giving teaching back to education: responding to the disappearance of the teacher. Phenomenology \& Practice, v. 6, n. 2, p. 35-49, 2012.

CECCON, C. et al. Conflitos na escola: modos de transformação: dicas para refletir e exemplos de como lidar. São Paulo: CECIP, 2009.

DEBARBIEUX, E.; BLAYA, C. (Orgs.). Violência nas escolas e políticas públicas. Brasília, DF: Unesco, 2002.

FROTA, A. M. M. C. Diferentes concepções da infância e adolescência: a importância da historicidade para sua construção. Estudos e Pesquisas em Psicologia, v. 7, n. 1, p.147-60, jun. 2007.

GOLDENBERG, M. A arte de pesquisar: como fazer pesquisa qualitativa em Ciências Sociais. Rio de Janeiro: Record, 2004.

HORTAS, Maria João. Educação e imigração: a integração dos alunos imigrantes nas escolas do ensino básico do centro histórico de Lisboa. Lisboa: Observatório da Imigração, 2013.

LAPASSADE, G. As microssociologias. Brasília, DF: Liber Livros, 2005.

MARTINS, A. M.; BRAVO, M. H.; OLIVEIRA, R. S. Relações de convivência, situações de conflito, indisciplina e violência em escolas públicas: análise de implementação de um programa de governo. Curitiba: Appris, 2018.

MARTINS, A. M. MACHADO, C. BRAVO, M. H. O que revela a Prova Brasil sobre situações de conflitos em escolas públicas? Cenários delineados pela visão de docentes. ETD - Educação Temática Digital, v. 17, série 3, p. 473-87, 2016. 
PORTUGAL. Despacho Normativo No 20/2012. Diário da República, 3 out. 2012.

SÃO PAULO (Estado). Secretaria de Estado da Educação. Resolução $S E N^{\circ} 19$, de 12, de fevereiro de 2010. Institui o Sistema de Proteção Escolar na rede estadual de ensino de São Paulo e dá providências correlatas. São Paulo, CENP/DRHU, 2010.

SEBASTIÃO, J. Violência na escola, processos de socialização e formas de regulação. Sociologia, Problemas e Práticas, n. 71, p. 23-37, jan. 2013. https://doi.org/10.7458/SPP2013712328

SEBASTIÃO, J.; ALVES, M. G.; CAMPOS, J. Violência na escola: das políticas aos quotidianos. Sociologia, Problemas e Práticas, n. 41, Oeiras, p. 37-62, jan. 2003.

SEBASTIÃO, J.; ALVES, M. G.; CAMPOS, J. Violência na escola e sociedade de risco: uma aproximação ao caso português. In: SEBASTIÃO, J. (Org.). Violência na escola: tendências, contextos e olhares. Santarém: Cosmos, 2010. pp. 15-42.

SLONJE, R.; SMITH, P. K. Cyberbullying: Another main type of bullying? Scandinavian Journal of Psychology, v. 49, n. 2, p. 147-54, apr. 2008. https://doi.org/10.1111/j.1467-9450.2007.00611.x

VASCONCELOS, I. C. O. Aprender a conviver, sem violência: o que dá e não dá certo? Ensaio: Avaliação e Políticas Públicas em Educação, v. 25, n. 97, p. 897-917, out/dez. 2017. https://doi.org/10.1590/s0104-40362017002501180

VENTURA, A.; VICO, B. P.; VENTURA, R. Bullying e formação de professores: contributos para um diagnóstico. Ensaio: Avaliação e Políticas Públicas em Educação, v. 24, n. 93, p. 990-1012, out./dez. 2016. https://doi.org/10.1590/S0104-403620160004000010

\section{Informações das autoras}

Ângela Maria Martins: Doutora. Professora Titular do Programa de Pós-Graduação em Educação e do Mestrado Profissional Formação de Gestores Educacionais da Universidade Cidade de São Paulo (UNICID). Pesquisadora da Fundação Carlos Chagas. Contato: ange.martins@uol.com.br

Mariana Gaio Alves: Doutora. Professora Auxiliar com Agregação no Instituto de Educação da Universidade de Lisboa (IE-UL). Investigadora na Unidade de Investigação e Desenvolvimento em Educação (UIDEF) e Formação do IE-UL. Contato: mga@ie.ulisboa.pt 